\title{
In vitro antifungal activity and phytochemical characterization of Eugenia uniflora, Libidibia ferrea and Psidium guajava
}

\author{
Magda Rhayanny Assunção Ferreira1, Rosilene Rodrigues Santiago', \\ Walicyranison Plínio Silva-Rocha ${ }^{1}$, Luanda Barbara Ferreira Canário de \\ Souza $^{1}$, Maria Graciela Icher Faria ${ }^{2}$, João Carlos Palazzo de Mello ${ }^{\circledR 3}$, Silvana \\ Maria Zucolotto Langassner', Guilherme Maranhão Chaves ${ }^{1}$, Eveline Pipolo \\ Milan $^{4}$, Terezinha Inez Estivalet Svidzinski ${ }^{2}$, Luiz Alberto Lira Soares ${ }^{1,5^{*}}$

\begin{abstract}
${ }^{1}$ Post-graduation Program in Pharmaceutical Science, Faculty of Pharmacy, Federal University of Rio Grande do Norte, Natal, RN, Brazil, ${ }^{2}$ Department of Clinical Analysis, Center of Biological Sciences,

State University of Maringá, Maringá, PR, Brazil, ${ }^{3}$ Department of Pharmacy and Pharmacology, Health Sciences Center, State University of Maringá, Maringá, PR, Brazil, ${ }^{4}$ Department of Infectology,

Health Sciences Center, Federal University of Rio Grande do Norte, Natal, RN, Brazil, ${ }^{5}$ Postgraduation Program in Pharmaceutical Science, Federal University of Pernambuco, Recife, PE, Brazil
\end{abstract}

\begin{abstract}
The aim of this study was evaluate the in vitro antifungal activity of crude extracts from Eugenia uniflora, Libidibia ferrea and Psidium guajava. The extracts were obtained by turbo-extraction using water (AQ) or acetone-water (AC-W) $(7: 3, \mathrm{v} / \mathrm{v})$ as solvents and lyophilized to obtain the crude extracts (CE). The CE were characterized by UV-Vis, TLC and HPLC. The activity of CEs was investigated against clinical isolates of Candida spp. and the Minimum Inhibitory Concentration (MIC), MIC $_{50}$ and $\mathrm{MIC}_{90}$ were determinated. The analysis by TLC showed that all CEs presented polyphenols (flavonoids and tannins). The CEs from E. uniflora showed higher amount of polyphenols $(30.35 \pm 2.15 \%, \mathrm{AC}-\mathrm{W})$ and the HPLC analysis revealed the tannins in all extracts. The CEs of E. uniflora showed MIC range from 1.9 to $500.0 \mu \mathrm{g} / \mathrm{mL}$, and lower values of $\mathrm{MIC}_{50}$ and $\mathrm{MIC}_{90}$ against non-albicans Candida isolates. Regarding L. ferrea and P. guajava, the results showing MIC from 3.9 to $1000.0 \mu \mathrm{g} / \mathrm{mL}$ (CE-AQ) against $C$. albicans. The results demonstrate antifungal performance from $C E$ against various species of Candida spp., suggesting that the herbal species may be use as new potential antifungal agents. Additionally, the polyphenol content can play a pivotal role in the antifungal properties of CE.
\end{abstract}

Keywords: Medicinal plants. Herbal extracts. Polyphenols. Candida isolates. Oral candidiasis.

\section{INTRODUCTION}

Oral candidiasis is an opportunistic infection, which begins by proliferation of endogenous commensal yeasts that inhabit the oral cavity. The oral tissue is the main way to various microorganisms, including Candida spp.. In healthy individuals, the immune defenses limit the

*Correspondence: L. A. L. Soares, Laboratory of Pharmacognosy, Department of Pharmaceutical Sciences, Federal University of Pernambuco - UFPE, Prof. Arthur de Sá, s/n, Cidade Universitária, 50740521, Recife-PE, Brazil.E-mail: phtech@uol.com.br proliferation of pathogenic microorganisms, reducing the connection with these tissues (Williams, Lewis, 2011). However, under certain conditions, these fungi may take the pathogenic form, especially in a group specific of patients, such as patients with transplant recipients, with Acquired Immunodeficiency Syndrome (AIDS) and resistant to conventional antifungal (Chaves et al., 2013).

Treatment with immunosuppressive depresses the host defense response, meaning a risk to oral infection, besides the association with other complications. In 
patients taking this type of treatment, such as transplant patients, the pathogens most likely to oral are local destruction and opportunistic infections appear due to the inability of the immune system to suppress and destroy such pathogens (Rojas et al., 2012).

The presence of lesions in the oral cavity can be considered as a risk factor for the development of oral infections, such as candidiasis (Sankari et al., 2015). In these cases, candidiasis can become invasive, being an important cause of morbidity and mortality caused by fungal infections that are particularly frequent in the first 6 months after the transplant (Shoham, Marr, 2012).

Candida albicans is the principal microorganism associated with this type of infection, although other species such as $C$. parapsilosis, $C$. tropicalis, $C$. glabrata, C. guilliermondii, C. lusitaniae and C. krusei also are considered pathogenic (Sardi et al., 2013), in addition, the species $C$. dubliniensis has been associated (Chaves et al., 2013; Sardi et al., 2013).

The increasing number of fungal infections has created a need for new antifungal agents. Several drugs such as polyenes (amphotericin B) are toxic; so becomes the appearance of azoles (fluconazole, ketoconazole, voriconazole), these are inexpensive, but Candida albicans and non-albicans Candida species have become resistance; echinocandins (caspofungin, micafungin and anidulafungin) have low toxicity and few drug interactions; and, fluoropyrimidines and others, may be interfere with some of the virulence factors of Candida species (Dimopoulos et al., 2013). Furthermore, many of these drugs have limitations such as narrow spectrum of action, side effects and toxicity. Therefore, the excessive and indiscriminate use of antifungal conventional agents increases the development of resistant, complicating the treatment of infections (Wille et al., 2013).

In this context, natural products arise as an important and promising source for the discovery of novel antifungal agents (Ferreira et al., 2013). Since these products have traditionally been used in controlling various diseases, as they are sources of multiple active compounds possessing therapeutic properties and are part of different synthesis of various natural products (Liu et al., 2012). Furthermore, the use of native plant species can be an economical alternative to the use of sustained region.

The aim of the present study was to characterize and evaluate the in vitro antifungal activity against clinical isolates from the oral cavity of kidney transplant recipients of crude extracts of Eugenia uniflora, Libidibia ferrea and Psidium guajava.

\section{MATERIAL AND METHODS}

\section{Plant material}

Samples of E. uniflora (leaves), L. ferrea (stem bark), and $P$. guajava (leaves) were collected in the states of Pernambuco and Rio Grande do Norte. Voucher specimens were deposited at the Agronomy Institute of Pernambuco (IPA) and the Department of Botany at the Federal University of Rio Grande do Norte (UFRN), under numbers 11763,88145 and 8214, respectively.

\section{Preparation of crude extracts}

The extracts were obtained by turbo-extraction with four extractive cycles of $1 \mathrm{~min}$ interspersed with $4 \mathrm{~min}$ of pause $[10 \%(\mathrm{w} / \mathrm{v})$ of dried and ground raw material], using water or acetone: water $(7: 3, \mathrm{v} / \mathrm{v})$ as solvents. The extracts were filtered and concentrated under reduced pressure in an evaporator (RV10 Basic, IKA ${ }^{\circledR}$ ) for complete elimination of the organic solvent. The residue was frozen $\left(-80^{\circ} \mathrm{C}, 3\right.$ days) and then lyophilized (Model L101, Liotop $\left.{ }^{\circledR}\right)$ to yield a crude extracts (CEs).

\section{Phytochemical analysis: Thin Layer Chromatography (TLC)}

Pre-coated TLC silica gel 60-F254 aluminum plates $(10 \mathrm{~cm} \times 10 \mathrm{~cm} ; 250 \mu \mathrm{m}$ thickness; MachereyNagel $\left({ }^{\circledR}\right)$ were used. The plates were developed using ethyl acetate: formic acid: water $(90: 5: 5, \mathrm{v} / \mathrm{v} / \mathrm{v})$ as the mobile phase. The chamber was saturated with the mobile phase at room temperature $\left(25 \pm 2{ }^{\circ} \mathrm{C}\right)$ for 15 min. After development, the plates were dried and the compounds were visualized after derivatization by spraying the NEU+PEG reagent for flavonoids and hydolysable tannins, and vanillin chloride for condensed tannins. Were used as standards: quercetin, gallic acid and catechin, respectively, for flavonoids, hydrolysable tannins and condensed tannins (Bezerra et al., 2018).

\section{Determination of Total Polyphenol Content}

The methods described by the Brazilian Pharmacopeia (Brazil, 2010) for the determination 
of Total Polyphenol Content (TPC) were used as guidelines for analyses of crude extracts and standard (pyrogallol, 98\%; Sigma-Aldrich ${ }^{\circledR}$ ). Solutions of pyrogallol $(1000.0 \mu \mathrm{g} / \mathrm{mL})$ and crude extracts $(1000.0$ $\mu \mathrm{g} / \mathrm{mL})$ were prepared in distilled water. Each solution (at the appropriate dilution) was transferred to a $25 \mathrm{~mL}$ volumetric flask containing distilled water $(10 \mathrm{~mL})$ and the Folin-Ciocalteu (Cinética $\left.{ }^{\circledR}\right)$ reagent $(1 \mathrm{~mL})$; the volume was completed with $29 \%$ anhydrous sodium carbonate (w/v). The samples were measured at $760 \mathrm{~nm}$ in an ultraviolet/visible spectrophotometer (Micronal ${ }^{\circledR}$ ) after $30 \mathrm{~min}$ the addition of the last reagent. Distilled water was used as the blank. The experiments were carried out in triplicate.

\section{High-Performance Liquid Chromatography (HPLC) analysis}

The crude extracts were analyzed by HPLC using a system Ultimate 3000 (Thermo Scientific ${ }^{\circledR}$ ) equipped with a binary pump (HPG3x00RS, Thermo Fisher Scientific $\left({ }^{\circledR}\right)$, autosampler (ACC3000, Thermo Fisher Scientific $\left.{ }^{\circledR}\right)$ and diode array detector (DAD; Thermo Fisher Scientific ${ }^{\circledR}$ ). Chromeleon 6.0 (Dionex ${ }^{\circledR}$ ) software was used for data acquisition and processing. The chromatographic separation was performed using a C18 column $\left(250 \mathrm{~mm} \times 4 \mathrm{~mm}\right.$ i.d., $5 \mu \mathrm{m}$; Dionex $\left.{ }^{\circledR}\right)$, equipped with a pre-column with the same material $\left(4 \mathrm{~mm} \times 3.9 \mu \mathrm{m}\right.$, Phenomenex $\left.{ }^{\circledR}\right)$. The mobile phase consisted by solvent A (purified water, Purelab Classic UV, Elga ${ }^{\circledR}$ ) and solvent B (methanol, HPLC grade, Tedia $\left.{ }^{\circledR}\right)$, both acidified with $0.05 \%$ trifluoracetic acid (Vetec ${ }^{\circledR}$ ) with flow rate at $0.8 \mathrm{~mL} / \mathrm{min}$, according to the following gradient program: $20-22.5 \% \mathrm{~B}(10 \mathrm{~min})$, $22.5-40 \%$ B (10 min), 40-75\% B (5 min), 75-20\% B (3 min) and $20 \%$ B (4 min).

The content of substances found in all crude extracts was determined from the calibration curves of gallic acid ( $96 \%$ of purity), catechin (98\% of purity), ellagic acid (95\% of purity, from tree bark), myricitrin (99\% of purity) and quercetin (98\% of purity), all standards purchased from Sigma ${ }^{\circledR}$ (USA). The determination of contents was carried out in triplicate.

The crude extracts of E. uniflora, L. ferrea and $P$. guajava as well as the standards were dissolved in water and filtered through a $0.45 \mu \mathrm{m}$ membrane (MachereyNagel $\left.{ }^{\circledR}\right)$ prior to sample injection $(20 \mu \mathrm{L})$. The peaks of substances in the crude extract were initially identified by comparing the retention times and UV spectra. After that, the peaks were confirmed by spiking the sample with a small amount of the standards.

\section{In vitro studies: Antifungal Assay}

The isolates from oral colonization, were obtained of the 88 patients from two different geographic regions of Brazil (69 from Natal - Rio Grande do Norte and 19 from Maringá - Paraná). Only patients who agreed to take part on a surveillance confidential study, in accordance to the Local Research Ethics committee from The Onofre Lopes University Hospital, approved under the number 152/07, were enrolled in this study. The species were identified in acordance with studies of (da Silva-Rocha et al., 2014).

\section{Preparation of the yeast suspension}

To prepare the inoculum, yeast cells were suspended in sterile saline solution ( $\mathrm{SSS}, 0.9 \%$ of $\mathrm{NaCl}$ ) vortexing and the concentration was adjusted at $90 \%$ transmittance in $530 \mathrm{~nm}$ spectrophotometer (Bausch \& Lomb $\left.{ }^{\circledR}\right)$. The turbidity was adjusted according to 0.5 tube of the McFarland scale, compatible with 1.0-5.0 x 106 colony-forming units per $\mathrm{mL}(\mathrm{CFU} / \mathrm{mL})$. From this suspension, two new dilutions were performed: the first of 1:50 in sterile saline solution and a second dilution of 1:20 in RPMI-1640 medium (Gibco $\left.{ }^{\circledR}\right)$.

\section{Preparation of the culture medium}

The RPMI-1640 medium (Gibco $\left.{ }^{\circledR}\right)$ was prepared together with a buffer solution of morpholino propanesulfonic acid-MOPS (Sigma-Aldrich ${ }^{\circledR}$ ) and supplemented with 2\% Glucose (Sigma-Aldrich ${ }^{\circledR}$ ), then stabilizing the $\mathrm{pH}$ of this solution to 7.0. Then, the medium was sterilized by membrane filtration porosity of $0.22 \mu \mathrm{m}$ (Milipore ${ }^{\circledR}$ ). After filtration, an aliquot was separated for the sterility at $37{ }^{\circ} \mathrm{C}$ for 24 hours. Subsequently, the medium was stored at temperature between $2-5^{\circ} \mathrm{C}$ until use.

\section{Preparation of samples for analysis}

To prepare the samples, the crude extracts were weighed into eppendorfs and diluted with $950 \mu \mathrm{L}$ of water and $50 \mu \mathrm{L}$ of dimethylsulfoxide (DMSO, Synth $\left.{ }^{\circledR}\right)$ to yield the final concentration of $2000 \mu \mathrm{g} /$ $\mathrm{mL}$, which is the stock solution. The working range 
used for the MIC determination was from 1.9 to $1000.0 \mu \mathrm{g} / \mathrm{mL}$.

\section{The antifungal activity of crude extracts}

The susceptibility tests were carried out through the method of broth microdilution for fluconazole (Pfizer ${ }^{\circledR}$ ) according to the Clinical and Laboratory Standards Institute standard M27-A3 (CLSI, 2008) with modifications for natural products.

The tests were made in sterile plastic microplates (Nunclon $\left.{ }^{\circledR}\right)$ with 96 wells arranged in eight series from $\mathrm{A}$ to $\mathrm{H}$, each one with 12 wells numbered 1 until 12. Each line corresponded to a strain of yeast and received $100 \mu \mathrm{L}$ of the corresponding inoculum. The extracts were diluted in the medium used, on the proportion 1:2.

In wells of columns 2 to 11 was added aliquots of medium RPMI-1640 $(100 \mu \mathrm{L})$ and $200 \mu \mathrm{L}$ in column 12 . The extracts, $100 \mu \mathrm{L}$, was added in the columns 1 and 2 of the microplates. With the multichannel pipette, a serial dilution was performed starting from the second column, homogenizing and removing $100 \mu \mathrm{L}$ of the mixture (medium and extracts) and adding to the well of the next column. The procedure was repeated the same way, to up the column 10, discarding the remaining 100 $\mu \mathrm{L}$. In this way, the concentrations of crude extracts ranged from 1.9 to $1000.0 \mu \mathrm{g} / \mathrm{mL}$.

For each isolate, the following controls were included: negative (only RPMI-1640); positive (RPMI1640 plus inoculum, without antifungal addition) and diluent (DMSO and inoculum). In each microplate a strain of Candida parapsilosis (ATCC 22019) was included as reference yeast. The microplates mounted were incubated in stove at $35{ }^{\circ} \mathrm{C} / 48-72 \mathrm{~h}$ with daily monitoring. After $48 \mathrm{~h}$ the reading of the fluconazole test was performed in microplate reader (Asys Hitech $\mathrm{GmbH}\left({ }^{\circledR}\right)$, and after $72 \mathrm{~h}$ that of the plant extracts was made through visual comparison, by mirror reflex (Shinobu-Mesquita et al., 2011; Ferreira et al., 2013).

\section{Minimal Inhibitory Concentration (MIC)}

The Minimum Inhibitory Concentration (MIC) was considered as the smallest concentration of the extracts (E. uniflora, L. ferrea and P. guajava) or of fluconazole that inhibited $100 \%$ of the growth of each yeast, with reference to its respective positive control (n =3). The MIC50 and MIC90 were defined as the MIC that inhibited $50 \%$ and $90 \%$ of the isolates, respectively (Shinobu-Mesquita et al., 2011).

\section{RESULTS}

\section{Phytochemical Analyses of Crude Extracts}

The qualitative phytochemical profile by TLC of crude extracts (aqueous and acetone-water) from $E$. uniflora, L. ferrea and P. guajava showed the presence of polyphenols (hydrolysable tannins and flavonoids) in all extracts. The results of the assay of Folin-Ciocalteu for total phenolic content (TPC) are shown in Table I. A comparison of the average of TPC showed that the acetone-water extracts exhibited the highest content of polyphenols.

The chromatographic fingerprints of the crude extracts are shown in Figure 1. The peak correspondent to gallic acid was identified in all chromatograms, eluting at a retention time (Rt) of $9.5 \mathrm{~min}$ with maximum of absorbance at $270 \mathrm{~nm}$. In chromatographic profile obtained for CE of E. uniflora (Figure 1A), was possible identified the presence of a flavonoid myricitrin at 21.5 min. In the CE of L. ferrea (Figure 1B), was identified peak correspondent to catechin $(\mathrm{Rt}=17.5 \mathrm{~min})$, and others majorities peaks of derivative catechins, with maximum of absorbance at $280 \mathrm{~nm}$. And, in the CE of $P$. guajava (Figure 1C) was possible identified the presence of flavonoid quercetin at $\mathrm{Rt}=26.5 \mathrm{~min}$ and ellagic acid at $\mathrm{Rt}=28.5 \mathrm{~min}$, with maximum's absorptions at $355 \mathrm{~nm}$ and $254 \mathrm{~nm}$, respectively. The results found by HPLC corroborated with results by UV-Vis that showed the acetone-water extracts presented highest content of each compound analyzed.

In this study, three plant species (native from Northeastern of Brazil) widely used as medicinal by the population were screened against various yeasts from Candida species, such as C. albicans, C. krusei, $C$. dubliniensis, $C$. glabrata and others. All crude extracts exhibit an inhibitory potential with broad spectrum, as they inhibited all yeasts species tested.

Overall, the CE from E. uniflora species exhibited a significant antifungal activity against Candida spp. isolates from the oral cavity of kidney transplant patients. Concentrations between 3.9 and $1000.0 \mu \mathrm{g} /$ $\mathrm{mL}$ of aqueous crude extract prevented the growth of C. albicans isolated from the Natal-RN; and between 1.9 and $500.0 \mu \mathrm{g} / \mathrm{mL}$ as the isolates of $C$. albicans from Maringá-PR. Since the ranges of MIC were lower for 
TABLE I - Chemical content of marker by HPLC and Total polyphenol (TPC) by UV-Vis of crude extracts

\begin{tabular}{|c|c|c|c|c|c|c|}
\hline \multirow{2}{*}{ Compound } & \multicolumn{2}{|c|}{ E. uniflora $(\%)$} & \multicolumn{2}{|c|}{ L. ferrea (\%) } & \multicolumn{2}{|c|}{ P. guajava (\%) } \\
\hline & $\mathbf{A Q}$ & $\begin{array}{c}\text { AC-W } \\
(7: 3, v / v)\end{array}$ & $\mathbf{A Q}$ & $\begin{array}{c}\text { AC-W } \\
(7: 3, v / v)\end{array}$ & $\mathbf{A Q}$ & $\begin{array}{c}\text { AC-W } \\
(7: 3, v / v)\end{array}$ \\
\hline Gallic acid & $0.16(0.29)$ & $0.17(0.95)$ & $0.12(0.07)$ & $0.13(0.82)$ & $0.31(1.34)$ & $0.35(0.50)$ \\
\hline Myricitrin & $1.64(0.37)$ & $1.77(0.06)$ & - & - & - & - \\
\hline Catechin & - & - & $0.95(1.25)$ & 1.09 (1.36) & - & - \\
\hline Quercetin & - & - & - & - & $0.93(0.12)$ & $1.15(0.08)$ \\
\hline Ellagic acid & - & - & - & - & $0.23(0.22)$ & $0.24(0.41)$ \\
\hline TPC* & $25.13(0.83)$ & $30.37(2.15)$ & $22.79(1.12)$ & $25.69(0.39)$ & $20.55(0.16)$ & $22.23(0.69)$ \\
\hline
\end{tabular}

All data represented as mean (relative standard deviation) of three independent measurements. Values are expressed as percentages $(\mu \mathrm{g} / \mathrm{g})$ of each compound in the crude extracts. AQ: Aqueous; AC-W: Acetone:water. *Values expressed as pyrogallol equivalent (PE) per gram of crude extracts.

crude extract of type acetone: water $(7: 3, \mathrm{v} / \mathrm{v})$, remaining in the range of 1.9 to $1000.0 \mu \mathrm{g} / \mathrm{mL}$ in Natal-RN and 1.9 to $500.0 \mu \mathrm{g} / \mathrm{mL}$ in Maringá-PR. Regarding the MIC50, showed value of $62.5 \mu \mathrm{g} / \mathrm{mL}$ for C. albicans, those isolated from patients in the region of Natal; already isolates of the Maringá, the crude extract obtained with acetone: water (7:3) showed the lowest MIC50 (31.2 $\mu \mathrm{g} /$ $\mathrm{mL})$ compared to the aqueous extract. MIC90 values showed values for the crude extracts acetone:water (7:3) equal to $500.0 \mu \mathrm{g} / \mathrm{mL}$. In relation to the species of non- $C$. albicans Candida (non-C. albicans), the MIC50 was lowest and equal to $31.2 \mu \mathrm{g} / \mathrm{mL}$ for the crude extract aqueous and $15.6 \mu \mathrm{g} / \mathrm{mL}$ for crude extract acetone: water, suggesting that the species may be new potential antifungal agent (Table II).

Regarding to $L$. ferrea, the results were similar in the regions where the isolates were collected and the type of extract, with the same range of MIC values (between 3.9 to $1000.0 \mu \mathrm{g} / \mathrm{mL}$ and 3.9 to $500.0 \mu \mathrm{g} / \mathrm{mL}$, respectively, for $C$. albicans and non-C. albicans, both as acetonic and aqueous extracts). The MIC50 and MIC90 values were also compared the type of extracts analyzed $($ MIC50 $=125.0 \mu \mathrm{g} / \mathrm{mL}$ and MIC90 $=500.0$ $\mu \mathrm{g} / \mathrm{mL}$ for the C. albicans), and in relation to isolates of non-C. albicans the values of MIC50 $(15.6 \mu \mathrm{g} / \mathrm{mL})$ and MIC90 $(125.0 \mu \mathrm{g} / \mathrm{mL})$ were less for the aqueous extract.

For $P$. guajava, the results were similar to aqueous extracts of $E$. uniflora and $L$. ferrea in relation to the range of minimum inhibitory concentration, when observed across species C. albicans (3.9 - $1000.0 \mu \mathrm{g} /$ $\mathrm{mL})$. The extracts obtained with acetone: water $(7: 3)$ had lower range of MIC values in the isolates of non- $C$. albicans $(3.9-250.0 \mu \mathrm{g} / \mathrm{mL})$. The MIC50 and MIC90 for clinical isolates of $C$. albicans showed higher values as respectively 250.0 and $500.0 \mu \mathrm{g} / \mathrm{mL}$ (extract aqueous) and 125.0 to $250.0 \mu \mathrm{g} / \mathrm{mL}$ (Table II).

In relation the non-C. albicans species, variability was found in the MIC values against the same plant species. Moreover, the crude extracts obtained with acetone: water (7:3) showed better results when compared with $C$. albicans. The MIC values remained between 1.9 and $500.0 \mu \mathrm{g} / \mathrm{mL}$ to as extracts of E. uniflora; between 3.9 and $500.0 \mu \mathrm{g} / \mathrm{mL}$ for of $L$. ferrea and 3.9 and 250.0 $\mu \mathrm{g} / \mathrm{mL}$ for $P$. guajava (Table II). 

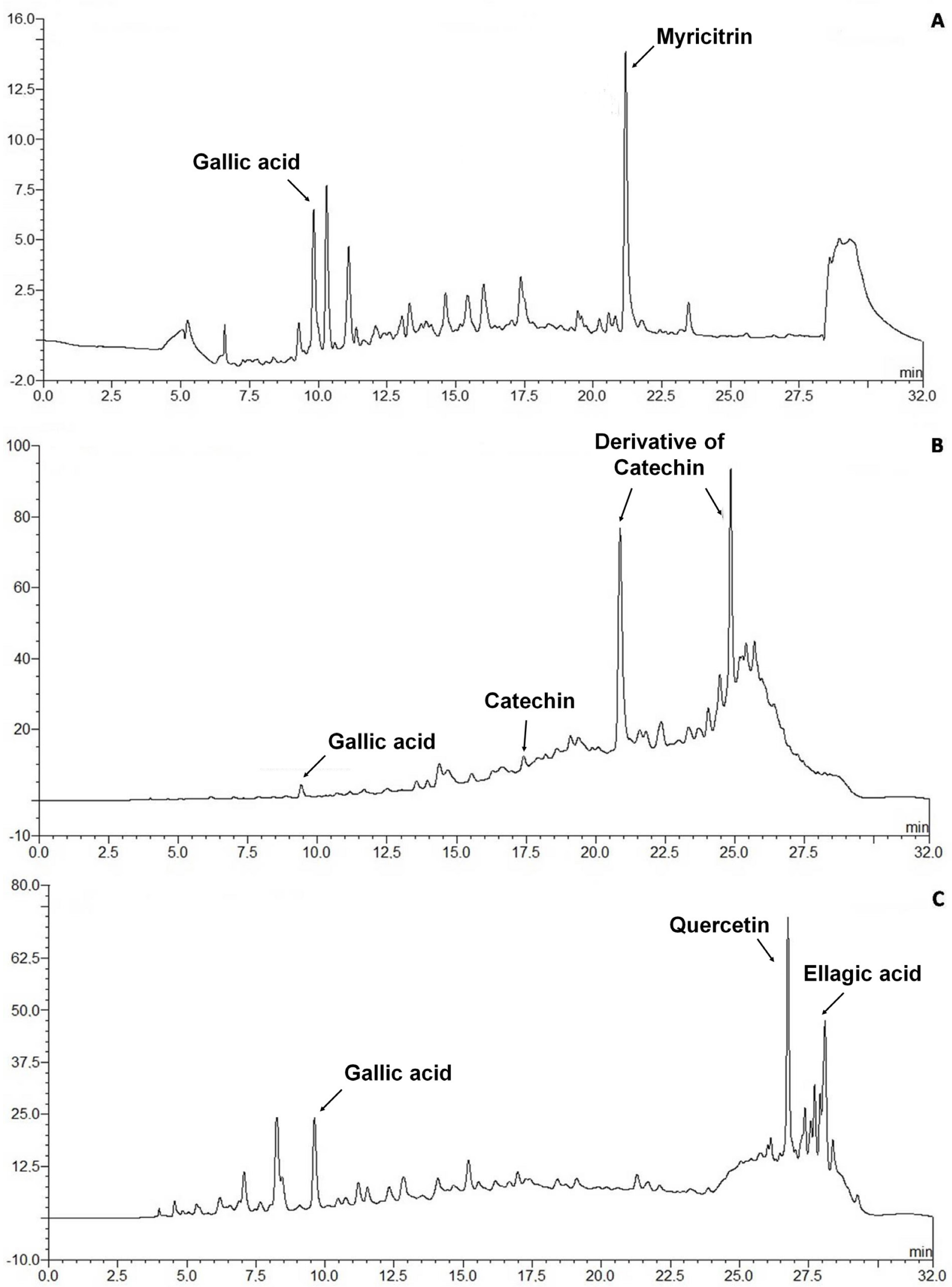

FIGURE 1 - Chromatographic fingerprints obtained by HPLC of crude extracts (acetone-water) from E. uniflora (A), L. ferrea (B) and P. guajava (C). 
TABLE II - Antifungal activity of crude extracts against Candida albicans and non-C. albicans isolated from the oral cavity of kidney transplant recipients

\begin{tabular}{|c|c|c|c|c|c|c|c|c|c|c|c|}
\hline \multirow{3}{*}{$\begin{array}{l}\text { Crude } \\
\text { Extract }\end{array}$} & \multirow{3}{*}{ Microorganisms } & \multirow{3}{*}{$\mathbf{n}$} & \multicolumn{3}{|c|}{ E. uniflora } & \multicolumn{3}{|c|}{ L. ferrea } & \multicolumn{3}{|c|}{ P. guajava } \\
\hline & & & $\begin{array}{l}\text { Range } \\
\text { of MIC }\end{array}$ & $\mathrm{MIC}_{50}$ & $\mathrm{MIC}_{90}$ & $\begin{array}{l}\text { Range } \\
\text { of MIC }\end{array}$ & $\mathrm{MIC}_{50}$ & $\mathrm{MIC}_{90}$ & $\begin{array}{l}\text { Range } \\
\text { of MIC }\end{array}$ & $\mathrm{MIC}_{50}$ & $\mathrm{MIC}_{90}$ \\
\hline & & & \multicolumn{3}{|c|}{$\mu \mathrm{g} / \mathrm{mL}$} & \multicolumn{3}{|c|}{$\mu \mathrm{g} / \mathrm{mL}$} & \multicolumn{3}{|c|}{$\mu \mathrm{g} / \mathrm{mL}$} \\
\hline \multirow{2}{*}{ AQ } & C. albicans & 74 & $\begin{array}{c}3.9- \\
1000.0\end{array}$ & 62.5 & 125.0 & $\begin{array}{c}3.9- \\
1000.0\end{array}$ & 125.0 & 500.0 & $\begin{array}{c}3.9- \\
1000.0\end{array}$ & 250.0 & 500.0 \\
\hline & non-C. albicans & 14 & $1.9-500.0$ & 31.2 & 500.0 & $3.9-500.0$ & 15.6 & 125.0 & $3.9-500.0$ & 31.2 & 250.0 \\
\hline \multirow{2}{*}{$\begin{array}{l}\text { AC-W } \\
(7: 3)\end{array}$} & C. albicans & 74 & $\begin{array}{c}1.9- \\
1000.0\end{array}$ & 31.2 & 500.0 & $\begin{array}{c}3.9- \\
1000.0\end{array}$ & 125.0 & 500.0 & $\begin{array}{c}7.8- \\
1000.0\end{array}$ & 125.0 & 250.0 \\
\hline & non-C. albicans & 14 & $1.9-500.0$ & 15.6 & 125.0 & $3.9-500.0$ & 31.2 & 250.0 & $3.9-250.0$ & 31.2 & 250.0 \\
\hline
\end{tabular}

N: Number of isolates; MIC: Minimum Inhibitory Concentration; lowest concentration of each drug able to inhibit $100 \%$ of the growth of each yeast. $\mathrm{MIC}_{50}$ and $\mathrm{MIC}_{90}$ : MIC of each extract able to inhibit $50 \%$ and $90 \%$ respectively of the number of isolates. The results presented are the mean obtained from three tests carried out.

\section{DISCUSSION}

The plant species natives from region Northeastern of Brazil are used in folk medicine or as commercial herbal. However, few ethnobotanic and ethnopharmacological studies have been described about the species related in this study (Biasi-Garbin et al., 2016; Ferreira et al., 2013). Besides, some few reports describing the antifungal activity of extracts or substances derived from plant on Candida species (Santos et al., 2013).

All the crude extracts studied had considerable amounts of phenolic compounds. The antifungal activity sometimes it's related with a presence of polyphenols (Shahzad et al., 2014), and polyphenols are an abundant source of structures containing phenolic hydroxyl that can be quantified by Folin-Ciocalteu method, like described in this study and others studies. Comparison of the average of TPC in crude extracts showed that the TPC from the aqueous extracts were all less than the TPC from the acetone-water extracts, corroborating with data from the literature that emphasize the maximization of polyphenols extraction when using the mixture acetone: water as a solvent (de Araújo et al., 2014; Martins et al., 2015).
The presence of gallic acid corroborates with results previously described in crude extracts from L. ferrea and P. guajava (de Araújo et al., 2014), but the presence in crude extract AC-W of E. uniflora was described at the first time. Moreover, the presence of derivative flavonoidics were described in others studies in with leaves of E. uniflora (Bezerra et al., 2018).

The literature regarding the antifungal activity against clinical isolates from the oral cavity of kidney transplant recipients of the species E. uniflora, $L$. ferrea and $P$. guajava is scarce. This study associated with ethnopharmacological uses of these species, may contribute to investigations as antifungal agents. Some studies related the activity of ethanolic extract from leaves of E. uniflora against dermatophytes (BiasiGarbin et al., 2016); thus, the association of the extract of E. uniflora to metronidazole showed a potential antifungal activity against $C$. tropicalis (Santos et al., 2013). Crude extracts from leaves of E. uniflora and $P$. guajava and stem barks of L. ferrea (water; ethanol: water, 1:1; acetone: water, 1:1) showed significant activity against four standard species of C. albicans, C. dubliniensis, C. glabrata and C. krusei (Ferreira et al., 2013). 
In relation to the Candida spp. clinical isolates (da Silva-Rocha et al., 2014) classified from the 88 yeasts obtained, like $77.6 \%$ of $C$. albicans, that was the most commonly isolated species on the oral cavity, as observed in studies where the frequency, up to $70 \%$ of isolates. Among the non-C. albicans species considered pathogenic such as $C$. tropicalis, $C$. glabrata, $C$. dubliniensis, C. orthopsilosis and C. metapsilosis has been detected in cases of oral candidiasis, especially those related to immunosuppression (Chaves et al., 2013). The use of clinical isolates from patients who are colonized or from fungal infections has been an important strategy to investigate potential of new antifungal agents.

The degree of susceptibility of yeasts obtained was different in relation to the species (C. albicans and non- $C$. albicans) and the type of extract studied. As the isolates of $C$. albicans from Natal were more resistant to E. uniflora, in both types of extracts evaluated (aqueous or acetone-water); however when evaluated non- $C$. albicans isolates, the crude extracts obtained with acetone-water were most effective, with average MIC equal to $56 \mu \mathrm{g} / \mathrm{mL}$ (range 1.9 to $250 \mu \mathrm{g} / \mathrm{mL}$ ).

For the species L. ferrea and P. guajava, both types of extract, for $C$. albicans were less resistant to those presented in the region of Maringá, highlighting the average MICs $86 \mu \mathrm{g} / \mathrm{mL}$ for the aqueous extract of L. ferrea (with range 3.9 to $500.0 \mu \mathrm{g} / \mathrm{mL}$ for aqueous and acetone-water extract) and $74 \mu \mathrm{g} / \mathrm{mL}$ for extract acetone-water of $P$. guajava (with range 3.9 to 500.0 $\mu \mathrm{g} / \mathrm{mL}$ for aqueous extract and 3.9 to $250 \mu \mathrm{g} / \mathrm{mL}$ for acetone: water extracts). In accordance with the values of MIC and the MIC50 and MIC90 values, it's possible affirms that the crude extract from E. uniflora, L. ferrea and $P$. guajava demonstrated strong antifungal activity (Shinobu-Mesquita et al., 2011; Ferreira et al., 2013).

Based on these findings, the crude extracts of $E$. uniflora, L. ferrea and P. guajava are optimistic since there was antifungal activity with low concentrations of crude extract. It is possible that after purification steps to achieve the required concentration antifungal activity is less than the one obtained in this work. Thus, further studies are needed to purify fractions or components, followed by new susceptibility testing in order to search new alternatives of antifungal drugs available to the population.

\section{ACKNOWLEDGEMENTS}

The authors are grateful to Coordenação de Aperfeiçoamento de Pessoal de Nível Superior (CAPESPROCAD/NF, 2008), Fundação de Amparo à Ciência do Estado de Pernambuco FACEPE (APQ-0493-4.03/14) and Conselho Nacional de Desenvolvimento Científico e Tecnológico CNPq for financial support in the form of grants (308386/2015-9) and fellowship awards.

\section{CONFLICTS OF INTEREST}

The authors declare that the research was conducted in the absence of any commercial or financial relationships that could be construed as a potential conflict of interest.

\section{REFERENCES}

Bezerra ICF, Ramos RTM, Ferreira MRA, Soares LAL. Chromatographic profiles of extractives from leaves of Eugenia uniflora. Rev Bras Farmacog. 2018;28(1):92-101.

Biasi-Garbin RP, Demitto Fde O, Amaral RC, Ferreira MR, Soares LA, Svidzinski TI, et al. Antifungal potential of plant species from brazilian caatinga against dermatophytes. Rev Inst Med Trop. 2016;58:18.

Brazil. Farmacopeia Brasileira. Brasil: Anvisa; 2010.

Chaves GM, Diniz MG, da Silva-Rocha WP, de Souza LBFC, Gondim LAM, Ferreira MAF, et al. Species distribution and virulence factors of Candida spp. isolated from the oral cavity of kidney transplant recipients in Brazil. Mycopathologia. 2013;175(3):255-263.

CLSI. Clinical Laboratory Standard Institute. Reference Method for Broth Dilution Antifungal Susceptibility Testing of Yeasts. Third ed. Wayne: CLSI; 2008.

da Silva-Rocha WP, Lemos VLB, Svidizisnki TIE, Milan EP, Chaves GM. Candida species distribution, genotyping and virulence factors of Candida albicans isolated from the oral cavity of kidney transplant recipients of two geographic regions of Brazil. BMC Oral Health. 2014;15(14):20.

de Araújo AA, Soares LAL, Ferreira MRA, de Souza Neto MA, da Silva GR, de Araújo Jr RF, et al. Quantification of polyphenols and evaluation of antimicrobial, analgesic and anti-inflammatory activities of aqueous and acetone-water extracts of Libidibia ferrea, Parapiptadenia rigida and Psidium guajava. J Ethnopharmacol. 2014;156:88-96. 
Dimopoulos G, Anastasia A, Apostolos A, Vincent J-L. How to select an antifungal agent in critically ill patients. J Crit Care. 2013;28(5):717-727.

Ferreira MRA, Santiago RR, Langassner SMZ, Mello JCP, Svidzinski TIE, Soares LAL. Antifungal activity of medicinal plants from Northeastern Brazil. J Med Plants Res. 2013;7(40):3008-3013.

Liu Q, Pellens K, Wang Y, Wang W, Thevissen K, Liang Q, et al. Antifungal activity in plants from Chinese traditional and folk medicine. J Ethnopharmacol. 2012;143(3):772-778.

Martins N, Barros L, Henriques M, Silva S, Ferreira ICFR. Activity of phenolic compounds from plant origin against Candida species. Ind Crop Prod. 2015;74(2015):648-670.

Rojas G, Bravo L, Cordero K, Sepúlveda L, Elgueta L, Díaz JC, et al. Integrity of the Oral Tissues in Patients with SolidOrgan Transplants. J Transplant. 2012;2012.

Sankari SL, Gayathri K, Balachander N, Malathi L. Candida in potentially malignant oral disorders. J Pharm Bioall Sci. 2015;7(Suppl 1):S162-S164.

Santos KKA, Matias EFF, Tintino SR, Souza CES, Braga MFBM, Guedes GMM, et al. Enhancement of the antifungal activity of antimicrobial drugs by Eugenia uniflora L. J Med Food. 2013;16(7):669-671.
Sardi JC, Scorzoni L, Bernardi T, Fusco-Almeida AM, Mendes Giannini MJ. Candida species: current epidemiology, pathogenicity, biofilm formation, natural antifungal products and new therapeutic options. J Med Microbiol. 2013;62(Pt 1):10-24.

Shahzad M, Sherry L, Rajendran R, Edwards CA, Combet E, Ramage G. Utilising polyphenols for the clinical management of Candida albicans biofilms. Int J Antimicrob Ag. 2014;44(3):269-273.

Shinobu-Mesquita CS, Bertoni TA, Guilhermetti E, Svidzinski TIE. Antifungal activity of the extract of Curcuma zedoaria (Christm.) Roscoe, Zingiberaceae, against yeasts of the genus Candida isolated from the oral cavity of patients infected with the human immunodeficiency virus. Rev Bras Farmacog. 2011;21(1):128-132.

Shoham S, Marr KA. Invasive fungal infections in solid organ transplant recipients. Future Microbiol. 2012;7(5):639-655.

Wille MP, Guimaraes T, Furtado GHC, Colombo AL. Historical trends in the epidemiology of candidaemia: analysis of an 11-year period in a tertiary care hospital in Brazil. Mem Inst Oswaldo Cruz. 2013;108(3):288-292.

Williams D, Lewis M. Pathogenesis and treatment of oral candidosis. J Oral Microbiol. 2011;3:1-11.

Received for publication on $22^{\text {nd }}$ June 2018 Accepted for publication on $13^{\text {rd }}$ February 2019 